\title{
The importance of sex-worker interventions: the case of Avahan in India
}

Marie Laga, ${ }^{1}$ Christine Galavotti, ${ }^{2}$
Sundar Sundaramon, ${ }^{3}$ Rob Moodie

Since the very beginning of the HIV epidemic, sex workers have been at increased risk for HIV, because of multiple partners, and highly vulnerable because of environmental and structural barriers that prevent them from accessing services or having control over their activities. ${ }^{1}$ Experience with feasible and effective prevention programmes has been accumulating for more than 20 years. In Democratic Republic of Congo, ${ }^{2}$ Côte d'Ivoire $^{3}$ and Bolivia, ${ }^{4}$ HIV and or STI rates among sex workers declined as a result of individual interventions including condom promotion, STI care and risk-reduction messages. Experience from the Dominican Republic ${ }^{5}$ and India ${ }^{67}$ illustrated the effectiveness of contextual interventions to reduce the vulnerability of sex workers and create an enabling environment.

So far, large-scale implementation of sex-worker interventions to reduce either risks or vulnerability has lagged behind. Most countries today still do not have a national plan to address the needs for this population, and worldwide less than $50 \%$ of sex workers have access to a minimum of prevention services. ${ }^{18}$ India is clearly an exception!

The government of India has supported sex-worker interventions in many high-prevalence districts since the mid-1990s, adopting mainly individual risk-reduction strategies such as condom distribution and outreach. In 2005, the

${ }^{1}$ Institute of Tropical Medicine, Antwerp, Belgium ${ }^{2} \mathrm{US}$ Centers for Disease Control and Prevention, Atlanta, Georgia, USA ${ }^{3}$ Independent consultant and member technical panel AVAHAN, Chennai, India ${ }^{4}$ Victoria Health Promotion Foundation, Melbourne, Australia

Correspondence to Dr Marie Laga, Institute of Tropical Medicine, Nationalestraat 155, 2000 Antwerp, Belgium; mlaga@itg.be

\section{UN LOCKED}

This paper is freely available online under the BMJ Journals unlocked scheme, see http://sti.bmj.com/site/ about/unlocked.xhtml
Bill and Melinda Gates Foundation's Avahan India AIDS Initiative was launched to increase the coverage of interventions for most at-risk populations, adopting a more holistic approach to prevention for sex workers. Within 2 years of operation, Avahan had scaled up an HIV-prevention intervention across six states in India, achieving coverage of over $80 \%$ of the target population. In coordination with the government of India and 134 grass-roots Indian non-governmental organisations, the programme reaches over 200000 sex workers, 60000 men who have sex with men, 20000 injecting-drug users and over 5 million high-risk men. ${ }^{9}$ Careful programme monitoring at all levels has allowed Avahan to document programme coverage and quality, as described in the papers in this issue, and an ambitious plan to evaluate the prevention impact of Avahan is now under way. Initial results are promising, with notable decreases in STI and HIV among both the target populations and general population. ${ }^{10} 11$

With its focus on prevention, Avahan has stood in stark contrast to the treatment fervour that has swept the HIV community. While the world turned its attention to expanding access to antiretroviral therapy to people living with HIV/AIDS, Avahan relied on the power of epidemiology, structural intervention and community ownership, and set out to halt the HIV epidemic in India. Perhaps because the Avahan senior staff were drawn from the management and business world, they came to the task of HIV prevention with an enthusiasm and openmindedness constrained neither by politics nor by the received truths of the global HIV community. And they knew how to manage large-scale undertakings!

Three key principles have defined Avahan's work-data, community and a scaled approach. They started with the data, mapping as carefully as they could the patterns of the concentrated epidemic in India, identifying those areas with the majority of HIV cases and with low coverage of HIV prevention services. And they stayed with the data: once the strategy of targeting sex workers, men who have sex with men, male clients, longdistance truckers and injecting-drug users was outlined, data guided every decision. As members of the Technical Advisory Panel, we were regularly asked questions such as: are we in the right areas, are we reaching every sex worker, are the services of sufficient quality and intensity, what should we do differently, what do the data tell us? And based on the data collected, the Avahan team abandoned activities and redirected resources to activities that were more likely to have an impact at scale.

But if 'data' was the first element of the strategy, and 'scale' the second, then 'community' was clearly an equally, if not more important, third element. From its inception, Avahan strove to put the community of sex workers at the centre of the response. Sex workers were viewed not only as the key customers but also as the natural owners of the programme. The inspiration for this came from the Sonagachi Project, a project well known for its success in increasing condom use and decreasing sexually transmitted disease in West Bengal, India. ${ }^{7}$ The Sonagachi Project is led by sex workers in a model that has come to be known as communityled structural intervention.

Avahan began its community mobilisation efforts with the recruitment of community guides to help map the highrisk populations in the focal districts. Those data were shared with the community, and as STI treatment and condom distribution services began to be established, community members were engaged as peer educators and advisors. They advised on the location of drop-in centres and the hiring of doctors, and oversaw outreach. This participation facilitated access to key social networks and helped the project track the intensity and quality of programme exposure. As their involvement grew, sex workers began to identify with each other and see themselves as a community, and they increasingly came together to work on issues affecting the community as a whole. For example, with support from the programme, they formed violence response systems and strengthened their ability to negotiate with local police and power structures. ${ }^{12}$ Sex workers have now mobilised in small and large communities across the Avahan districts to claim their identities and their rights, to stand up against harassment and violence, and to hold 
government accountable for quality HIV prevention, testing and treatment services.

The prevention community is coming to terms with the complexity of HIV prevention and being urged to make better use of existing data, to ensure resources are directed to where the epidemic is and to what drives it, to address vulnerability and structural determinants, and to apply what we know works with sufficient quality, intensity and scale. ${ }^{8} 1314$ These are the principles that have characterised Avahan's approach from the start. The fact that, this many years into the epidemic, we are also rediscovering the importance of sex-worker interventions makes Avahan's achievement over the last 5 years even more remarkable. Avahan stands as a rare example of the enormous power of data and community-especially when working together-to challenge an epidemic and a mindset, and to overcome both.

The findings and conclusions in this report are those of the authors and do not necessarily represent the official position of the US Centers for Disease Control and Prevention.

\section{Competing interests None.}

Provenance and peer review Commissioned externally peer reviewed.

Accepted 27 November 2009

Sex Transm Infect 2010;86:i6-i7.

doi:10.1136/sti.2009.039255

\section{REFERENCES}

1. Vuylsteke B, Das A, Dallabetta G, et al. Preventing HIV among sex workers. In: Mayer K Pizer HF, eds. HIV prevention. London UK: Academic Press, 2008:376-406.

2. Laga M, Alary M, Nzila N, et al. Condom promotion, sexually transmitted diseases treatment, and declining incidence of HIV-1 infection in female Zairian sex workers. Lancet 1994;344:246-8.

3. Ghys PD, Diallo M0, Ettiegne-Traore V, et al. Increase in condom use and decline in HIV and sexually transmitted diseases among female sex workers in Abidjan, Côte d'lvoire, 1991-1998. AIDS 2002;16:251-8.

4. Levine WC, Revollo R, Kaune V, et al. Decline in sexually transmitted disease prevalence in female Bolivian sex workers: impact of an HIV prevention project. AIDS 1998;12:1899-906.

5. Kerrigan D, Moreno L, Rosario S, et al. Environmental-structural interventions to reduce HIV/ STI risk among female sex workers in the Dominican Republic. Am J Public Health 2006:96:120-5.
6. Jana S, Bandyopadhyay N, Mukherjee S et al. STD/HIV intervention with sex workers in West Benghal, India. AIDS 1998;12(B Suppl):101-8S

7. Basu I, Jana S, Rotheram-Borus MJ, et al. HIV prevention among sex workers in India. J Acquir Immune Defic Syndr 2004;36:845-52.

8. Bertozzi S, Laga M, Bautista-Arredondo S, et al. Making HIV prevention programmes work. Lancet 2008;373:831-44.

9. Chandrasekeran P, Dallabetta G, Loo V, et al. Evaluation design for large scale HIV prevention programs: the case of Avahan, the India AIDS Initiative. AIDS 2008;22(5 Suppl): 1-15S.

10. Reza-Paul S, Beattie T, Syed H, et al. Declines in risk behaviour and sexually transmitted infection prevalence following a community-led HIV preventive intervention among female sex workers in Mysore, India. AIDS 2008:22(5 Suppl):91-100S

11. Moses S, Ramesh B, Nagelkerke N, et al. Impact of an intensive HIV prevention programme for female sex workers on HIV prevalence among antenatal clinic attenders in Karnataka state, south India: an ecological analysis. AIDS 2008;22 (5 Suppl):101-8S.

12. Piot $\mathbf{P}$, Bartos $\mathrm{M}$, Larson $\mathrm{H}$, et al. Coming to terms with complexity: a call to action for HIV prevention. Lancet 2008:372:845-59.

13. Gupta G, Parkhurst J, Ogden J, et al. Structural approaches to HIV prevention. Lancet 2008:372:764-75.

\section{Avahan: the transition to a publicly funded programme as a next stage}

\section{Prasada J V R Rao}

Avahan the flag ship programme of the Bill \& Melinda Gates Foundation (BMGF) for the prevention of HIV in India was projected as a unique business model that brought private sector efficiency to a public health programme. However, within a period of 3 years after its launch, the programme already started planning for a phased withdrawal and a 'graceful transfer' into a publicly funded programme. ${ }^{1}$

Avahan with a US\$250 million project cost was effectively complementing the Government of India's efforts to control

UNAIDS, Regional Support Team for Asia and the Pacific, Bangkok, Thailand

Correspondence to Dr Prasada JVR Rao, 9th Floor, Block A, United Nations Building, Rajadamnern Nok Avenue, Bangkok 10200, Thailand; raojvrp@unaids.org

\section{UN LOCKED}

This paper is freely available online under the BMJ Journals unlocked scheme, see http://sti.bmj.com/site/ about/unlocked.xhtml
AIDS through its own publicly funded National AIDS Control Program (NACP). Avahan was tasked to deliver to scale, high quality prevention interventions to high-risk community groups in six high prevalence states and make an impact on the progression of the epidemic in these states.

Six years later, despite its impressive success in rapid scale up and efficient management of programme delivery, Avahan is coming under criticism for trying to wind up early from India, and worse, for experimenting with a model that is high cost in terms of unit costs of intervention. The programme, which aimed at ultimate community ownership of the interventions, has initiated the process of transfer before this objective is fully realised.

The feasibility of Avahan's proposed transition into a publicly funded programme can only be assessed against the background of the importance given to prevention programmes among high-risk groups in NACP.
India's national programme $e^{2}$ was ahead of its time in 1999 when it earmarked 14\% of its programme budget for 'targeted interventions' in the prevention programmes for high-risk populations. Four years later, when BMGF launched the Avahan programme, it had a ready-made model of focused interventions among these risk groups to adopt, refine and upgrade. The upgraded model of focused interventions was allotted $57 \%$ of the US $\$ 250$ million of committed resources for Avahan. ${ }^{3}$ The first phase of Avahan ended in 2008 with impressive impact results on the coverage of high-risk populations, strengthening prevention infrastructure and the delivery of services.

While the general impression was that Avahan will continue to deliver these services under the new business model, the BMGF had other priorities. The strategy of the Foundation seems to have shifted to the transfer of ownership to Government, much earlier than originally envisaged. In October 2006, less than 3 years after the launch, the mid-term review had already recommended 'exploring alternative positions to align the organisation with changing priorities as the program managers scale down their implementor role and focus more on packaging the learnings from Avahan' 3

The success definition of Avahan therefore shifted only to demonstrate 


\section{Key messages}

- International backpackers attending the clinic had higher rates of genital chlamydial infection than a local comparison population.

- International backpackers have high rates of partner change, hazardous levels of alcohol consumption and low rates of condom usage, creating an environment conducive to STI transmission.

- Backpackers should be a priority population for sexual health promotion and access to services.

Acknowledgements The authors would like to thank Heng Lu and Ben Judd for data management.

\section{Competing interests None.}

Ethics approval This study was conducted with the approval of the South Eastern Sydney Illawarra Area Health Service Ethics Committee.

Contributors CE developed the study idea and assisted with study design; HW analysed the data; AMM designed the study and wrote the manuscript; BD designed the study and edited the manuscript. All authors reviewed the study manuscript.

Provenance and peer review Not commissioned; externally peer reviewed.

\section{REFERENCES}

1. Hawkes S, Hart G, Bletsoe E, et al. Risk behaviour and STD acquisition in genitourinary clinic attenders who have traveled. Genitourin Med 1995;71:351-4.

2. Melbye $\mathbf{M}$, Biggar R. A profile of HIV-risk behaviours among travellers-a population based study of Danes visiting Greenland. Scand J Soc Med 1994;22:204-8.

3. Rogstad K. Sex, sun, sex and STIs: sexually transmitted infections acquired on holiday. BMJ 2004;329:214-17.
4. Richens J. Sexually transmitted infections and HIV among travellers: a review. Travel Med Infect Dis 2006;4:184-95.

5. Mercer C, Fenton K, Wellings K, et al. Sex partner acquisition while overseas: results from a British national probability survey. Sex Transm Infect 2007;83:517-22.

6. Hughes K, Downing J, Bellis $\mathrm{M}$, et al. The sexual behaviour of British backpackers in Australia. Sex Transm Infect 2009:85:477-82.

7. Cabada M, Echevarria J, Seas C, et al. Sexual behaviour of international travelers visiting Peru. Sex Transm Dis 2002;29:510-13.

8. Bloor M, Thomas M, Hood $\mathrm{K}$, et al. Differences in sexual risk behaviour between young men and women travelling abroad from the UK. Lancet 1998;352:1664-8.

9. Egan C. The sexual behaviours, condom use and factors influencing casual sex among backpackers and other international travellers. Can J Hum Sex 2001;10:41-58.

10. Tourism Research Australia. Backpackers in Australia. Belonnen, ACT: Tourism Research Australia, 2008. <http://www.tra.australia.com/content/documents/ Snapshots/2008/BackPacker 07 FINAL.pdf> (accessed 20 0ct 2009).

11. Department of Immigration and Citizenship. Australian Government. Canberra, 2009. http://www.immi.gov.au/visitors/working-holiday/visa-options.htm laccessed 12 June 2009)

12. Yallop S, Murray C, Egan C, et al. Safe in the sack - backpackers' sexual health project. Sydney: FPA Health, 2005.

13. National Health and Medical Research Council. Australian Alcohol Guidelines: Health risks and benefits, 2001. http://www.nhmrc.gov.au/publications/synopses/ ds9syn.htm (accessed 20 0ct 2009).

14. Arvidson M, Hellberg D, Mardh PA. Sexual risk behavior and history of sexually transmitted diseases in relation to casual travel sex during different types of journeys. Acta Obstet Gynecol Scand 1996;75:490-4.

15. Egan C. Sexual behaviour of international backpackers in the context of travel in Australia. PhD thesis. Sydney: Faculty of Arts and Social Sciences, University of New South Wales, 2009.

16. Chen M, Rohrsheim R, Donovan B. Chlamydia trachomatis infection in Sydney women. Aust NZ J Obstet Gynaecol 2005;45:410-13.

17. Carter S, Horn K, Hart G, et al. The sexual behaviour of international travelers at two Glasgow GUM clinics. Int J STD AIDS 1997;8:336-8.

18. Mendelsohn R, Astle L, Mann M. Sexual behaviour in travellers abroad attending an inner-city genitourinary medicine clinic. Genitourin Med 1996;72:43-6.

19. Bellis $\mathbf{M}$, Hughes $\mathrm{K}$, Dillon $\mathrm{P}$, et al. Effects of backpacking holidays in Australia alcohol, tobacco and drug use of UK residents. BMC Public Health 2007;7:1.

20. Bellis $\mathbf{M}$, Hughes K, Thomson R, et al. Sexual behaviour of young people in international tourist resorts. Sex Transm Infect 2004;80:43-7.

\section{Corrections}

Hettiarachchi N, Ashbee HR, Wilson JD. Prevalence and management of non-albicans vaginal candidiasis. Sex Transm Infect 2010;86:99-100. The surname of the first author was misspelled. The correct name is Hettiarachchi not Hetticarachchi. The journal apologises for this error.

Sex Transm Infect 2010;86:250. doi:10.1136/sti.2009.040386corr1

Jurstrand M, Christerson L, Klint M, et al. Characterisation of Chlamydia trachomatis by ompA sequencing and multilocus sequence typing in a Swedish county before and after identification of the new variant. Sex Transm Infect 2010;86:56-60. There was an error in the order of the references. The corrected version is available online.

Sex Transm Infect 2010;86:250. doi:10.1136/sti.2009.037572corr1

Bertozzi SM, Padian N, Martz TE. Evaluation of HIV prevention programmes: the case of Avahan. Sex Transm Infect 2010;86:i4-5. There were several errors in this editorial. Reference 9 referred to an unpublished paper by Vickerman, not to the paper by Pickles, which was published in the same supplement.

Secondly, the statement "Finally Ramesh et al came closest to examining the impact of Avahan on FSW using dynamic transmission models. They used prevalence from two crosssectional surveys..." is incorrect. Ramesh does not use a dynamic transmission model-this is referring to one of the two modelling papers. Ramesh uses a time-trend analysis from two cross sectional surveys.

Finally, the name Alary is misspelled Alery twice in the editorial.

The journal apologies for these errors.

Sex Transm Infect 2010;86:250. doi:10.1136/sti.2009.039263corr1

Laga M, Galavotti C, Sundaramon S, et al. The importance of sex-worker interventions: the case of Avahan in India. Sex Transm Infect 2010;86:16-7. The surname of the author Sundar Sundaramon was incorrectly spelt. The correct spelling is Sundararaman. 